\title{
Fatty acid, mineral content and antioxidant activities of Algerian fat bee pollen
}

\author{
Boulanouar Bakchiche ${ }^{1, \bigotimes}$, Hadjira Guenane ${ }^{1}$, Bihter $\operatorname{Sahin}^{2}$, Mehmet Öztürk ${ }^{2}$, \\ Mosad A. Ghareeb ${ }^{3}$ and Maria da Graça Miguel ${ }^{4}$ \\ ${ }^{1}$ Laboratory of Process Engineering, Laghouat University, Laghouat 03000, Algeria \\ ${ }^{2}$ Department of Chemistry, Faculty of Science Mugla Sitki Kocman University, Mugla, Turkey \\ ${ }^{3}$ Medicinal Chemistry Department, Theodor Bilharz Research Institute, Kornaish El Nile, Warrak El-Hadar, Imbaba \\ (P.O. 30), Giza 12411, Egypt \\ ${ }^{4}$ Universidade do Algarve, Faculdade de Ciências e Tecnologia, Departamento de Química e Farmácia, Mediterranean \\ Institute for Agriculture, Environment and Development, Campus de Gambelas, Faro 8005139, Portugal
}

\section{Article info}

Article history:

Received: $27^{\text {th }}$ May 2020

Accepted: $4^{\text {th }}$ November 2020

\section{Keywords:}

Antioxidants

Bee pollen

DPPH

GC/MS

Mineral content

\begin{abstract}
Bee pollen is known for its nutritional value, and therefore it is used in the treatment of some health disorders as food supplements. Herein, the chemical fatty acid profile and mineral contents of two Algerian bee pollen collected from different regions were investigated, along with their physicochemical properties such as specific gravity, refractive index, and acid, saponification, and iodine values. In addition, their total phenolic contents (TPC) were also investigated. Gas chromatography/mass spectrometry (GC/MS) analysis revealed that the bee pollens mainly contained palmitic (17.0 and $26.5 \%)$, oleic (8.5 and $10.1 \%)$, linoleic (15.7 and $12.6 \%$ ) and linolenic acids (27.2 and $26.3 \%)$, respectively. The saponification values were 178.54 and $175.73 \mathrm{mg} \mathrm{KOH} . \mathrm{g}^{-1}$, while the specific gravity 0.915 and 0.924 , the refractive index 1.465 and 1.464, and acid values 22.04, and $10.01 \mathrm{mg} \mathrm{KOH} . \mathrm{g}^{-1}$ oil. The iodine values were, however, 44.42 and $32.90 \mathrm{mg} \mathrm{I}_{2} \cdot \mathrm{g}^{-1}$ fat, respectively. Potassium and sodium were the main detected elements in both pollen samples with variable percentages. In the DPPH assay, the $\mathrm{IC}_{50}$ was 4.88 and $1.73 \mathrm{mg} \cdot \mathrm{mL}^{-1}$ for samples 1 and 2 , respectively, ABTS and phosphomolybdenum assays supported DPPH assay results. It was concluded that the fat part of bee pollen by honeybees (Apis mellifera L.) is a promising source of naturally occurring antioxidants and nutrients.
\end{abstract}

(C) University of SS. Cyril and Methodius in Trnava

\section{Introduction}

Honeybees (Apis mellifera L.) produce bee pollen to feeding their larvae at the early stage. Bee pollen, constituting a mixture of pollens from flowers belonging to diverse species, and are agglutinated by nectar and honeybee mouth secretions that contain diverse enzymes (e.g., amylase, catalase) (Campos et al. 2008; Denisow and Denisow-Pietryk 2016). Although the great chemical variability of bee pollen owing to the heterogeneity of plant species in diverse geographic zones and the inherent climatic diversity where hives are located, it is mainly constituted by proteins, essential amino acids, reducing sugars, lipids, nucleic acids (particularly RNA), and crude 


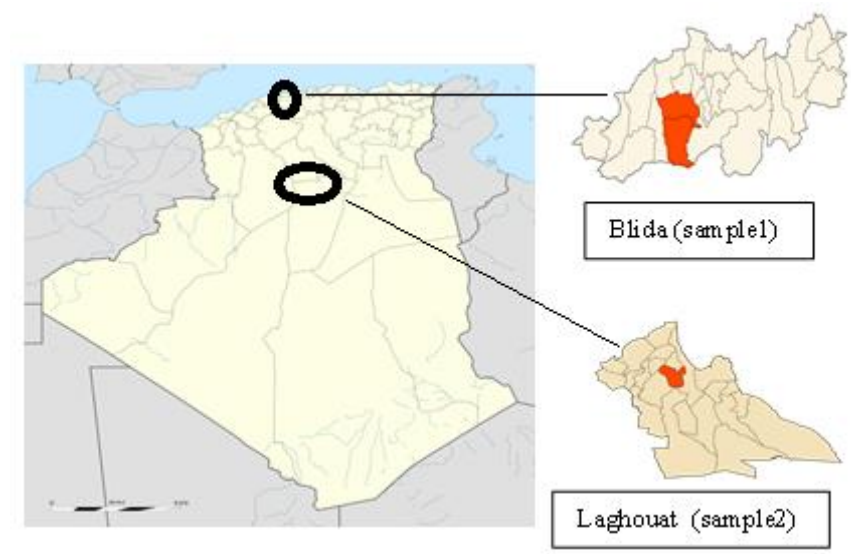

Fig. 1. Map of the sampling area (Sample 1: NA and Sample 2: SA).

fibre. This means that the variability found is mostly quantitative (Denisow and Denisow-Pietryk 2016). This composition makes bee pollen high value in human nutrition (Denisow and DenisowPietryk 2016; Abdelnour et al. 2019). Besides major compounds, bee pollens include minerals, vitamins, fatty acids, phytosterols, terpenes, phenols and flavonoids, and carotenoid pigments. The bioactivities of bee pollen such as antimicrobial, antioxidant, anti-inflammatory, anticarcinogenic, anti-allergenic, antiatherosclerotic, and hepatoprotective, can be attributed to the presence of those bioactive metabolites (Denisow and Denisow-Pietryk 2016). Such properties have led to the utilization of bee pollen as a valuable dietary supplement and with a great potential for being used as medicine (Denisow and Denisow-Pietryk 2016; Abdelnour et al. 2019).

Despite the well-known importance of bee pollen, the Algerian bee pollen has a lack of information (Rebiai and Lanez 2012; 2013 and 2014). The present short communication aimed at contributing to unravel on the mineral and fatty acid composition of the bee pollen collected from two different locations of Algeria. In addition, the total phenolic content and antioxidant activity were also reported.

\section{Experimental}

\section{Bee pollen and reagents}

Dried bee pollen was obtained in April 2019 from two different regions of Algeria. NA is from North
Algeria (Blida) in which Olea europeae, Eucalyptus sp. were present along with Pimpinella anisum, Trifolium repens, Daucus carota, Rubus sp., Acacia sp. and Eryngium sp.; and SA from South Algeria (Laghouat) (Fig. 1), in which Pergamum hermala, Trifolium sp., Echium, Acacia sp., and Ziziphus sp. could be found, according to the beekeepers' information.

All solvents, standards and reagents used in this study were of high analytical grade and purchased from Sigma-Aldrich (St. Louis, MO, USA).

\section{Fat extraction using the Soxhlet method}

One hundred gram of pollen was ground in a mortar and placed in a cartridge, which was introduced into the Soxhlet extractor using hexane $(350 \mathrm{~mL})$ as an extraction solvent. The operation consisted of several cycles until the complete extraction of the fat $(2 \mathrm{~h})$. Then, the solvent of the extract was evaporated using a rotary vacuum evaporator for recovering the fat extract (Converti et al. 2009).

\section{Preparation of extracts}

Each bee pollen sample $(10 \mathrm{~g})$ was dissolved in $50 \mathrm{~mL}$ of hexane and extracted three times with $100 \mathrm{~mL}$ of $60 \%$ aqueous methanol at room temperature $(2 \mathrm{~h})$. The mixture was centrifuged at 3,000 rpm for five min. The lower phase was collected and used to analyze total phenolic content.

\section{Determination of physicochemical properties}

Specific gravity and refractive index were determined at room temperature $\left(25{ }^{\circ} \mathrm{C}\right)$ using a densitometer and a refractometer, respectively. Acid, saponification, and iodine values were determined according to standard procedure (AOCS 2003).

\section{Preparation of methyl esters of fatty acids}

The fat extract $(25.0 \pm 0.1 \mathrm{mg})$ was weighed in a $25 \mathrm{~mL}$ volumetric flask and $1.5 \mathrm{~mL}$ of $0.5 \mathrm{M}$ methanolic sodium hydroxide was added and heated in a water bath, at $50{ }^{\circ} \mathrm{C}$, for five min. 
Then, $1.5 \mathrm{~mL}$ of $\mathrm{BF}_{3}$ (boron trifluoride)-methanol was added, and the mixture was heated for $5 \mathrm{~min}$, at $80{ }^{\circ} \mathrm{C}$. After cooled, the flask was completed with a saturated solution of sodium chloride. Then the mixture was transferred to a separator funnel, $5 \mathrm{~mL}$ of hexane was added, the funnel was shaken and then left to stand for layer separation. The upper hexane layer was submitted to evaporation using a rotary evaporator. Before analysis with GC/MS, the mixture was diluted with hexane (1:25; v/v) (Öztürk et al. 2014).

\section{Analysis of methyl esters of fatty acids by gas chromatography/mass spectrometry (GC/MS)}

GC/MS analyses of fatty acids were performed using a Varian Saturn 2100T equipped with an electron ionizer, and an ion trap analyzer and DB-1 MS fused silica nonpolar capillary column $(30 \mathrm{~m} \times 0.25 \mathrm{~mm}$ i.d., film thickness $0.25 \mu \mathrm{m})$. The carrier gas was helium. The injector and ion source temperatures were $250{ }^{\circ} \mathrm{C}$ and $120{ }^{\circ} \mathrm{C}$, respectively. The initial oven temperature was held at $100{ }^{\circ} \mathrm{C}$ for $5 \mathrm{~min}$, then increased up to $238{ }^{\circ} \mathrm{C}$ with $3{ }^{\circ} \mathrm{C} \cdot \mathrm{min}^{-1}$ increments and held at this temperature for $9 \mathrm{~min}$. The injection volume was $0.2 \mu \mathrm{L}$ with a split ratio of $1: 20,70 \mathrm{eV}$ ionization energy was used for EI-MS (electron ionizationmass spectrometry) spectra. The mass range was from $m / z$ 28-450 amu. The fatty acid methyl ester standard mixture (FAME Supelco ${ }^{\text {TM }} 37$ Catalog no: 47885-U) was used for the comparison and quantification of the GC chromatograms. The library search was also carried out using Wiley-2008 GC/MS libraries to identify fatty acids.

\section{Mineral Analysis of bee pollen}

For minerals determination, $0.5 \mathrm{~g}$ of each sample was taken and heated in a muffle furnace at $400{ }^{\circ} \mathrm{C}$. The ash obtained was cooled, dissolved in $5 \mathrm{~mL}$ of $6 \mathrm{~N} \mathrm{HCl}$ and allowed to stand for $30 \mathrm{~min}$. It was later filtered, and its volume made up to $50 \mathrm{~mL}$ with deionized water (Ullah et al. 2012). The elements $\mathrm{Fe}, \mathrm{Cu}, \mathrm{Pb}$, and $\mathrm{Ni}$, in previously mineralized samples were analyzed with an atomic absorption-emission spectrometer (Solaar 969, Unicam Ltd., Cambridge, UK). The $\mathrm{K}$ and $\mathrm{Na}$ contents were determined by using a PFP7
Industrial Flame Photometer (United Kingdom).

\section{Total phenolic content determination}

The total phenolics content of extracts was determined by the Folin \& Ciocalteu's method (Gao et al. 2000). Briefly, $0.1 \mathrm{~mL}$ diluted extract solution was shaken for $1 \mathrm{~min}$ with $200 \mu \mathrm{L}$ of Folin-Ciocalteu's reagent and $2 \mathrm{~mL}$ of distilled water. The mixture was shaken, and $2 \mathrm{~mL}$ of $20 \%$ $\mathrm{Na}_{2} \mathrm{CO}_{3}$ were added. After $30 \mathrm{~min}$, the absorbance at $750 \mathrm{~nm}$ was evaluated using a spectrophotometer (Beckman Coulter DU-640, CA, USA). The results were expressed as gallic acid equivalents.

\section{Determination of antioxidant potential}

DPPH free radical scavenging activity

Free radical scavenging capacity was measured using the DPPH assay, according to BrandWilliams et al. (1995). Briefly, $0.2 \mathrm{~mL}$ of extracts diluted in methanol was added to a $60 \mu \mathrm{M}$ DPPH in methanol $(1.8 \mathrm{~mL})$. The DPPH solution in the absence of the extract was used as the control, and methanol was used as blank. The samples were incubated for $1 \mathrm{~h}$ in the dark at room temperature, and the decrease in absorbance was spectrophotometrically measured at $515 \mathrm{~nm}$ (Shimadzu UV-B382). Measurements were performed in triplicate. The scavenging effect percentage was calculated from the formula: Percentage of inhibition (Eq. 1):

$[\%]=\left[\left(A b_{\text {control }}-A b s_{\text {sample }}\right) / A b s_{\text {control }}\right] \times 100$

The percentage was plotted against the samples, and $\mathrm{IC}_{50}$ values were estimated (concentration of samples able to scavenger $50 \%$ of the DPPH free radicals). The sample concentration providing $50 \%$ inhibition (IC50) was calculated from that graph.

Determination of antioxidant activity using ABTS cation radical scavenging activity

The ABTS radical cation decolorization method is based on the reduction of $\mathrm{ABTS}^{\circ+}$ radicals by antioxidants. A volume of $15 \mu \mathrm{L}$ of aqueous methanolic extract was added to $1.485 \mathrm{~mL}$ of $\mathrm{ABTS}^{\cdot+}$ solution, and the mixture was kept 
at $30{ }^{\circ} \mathrm{C}$. The absorbance was measured at $734 \mathrm{~nm}$. Measurements were performed in triplicate. The values were presented as $\mathrm{IC}_{50}$ values according to that reported for DPPH scavenging activity (Dorman and Hiltunen 2004).

Total antioxidant capacity measured through the phosphomolybdenum assay

The total antioxidant capacity was determined by the method of Prieto et al. (1999). The methanolic extract $(0.3 \mathrm{~mL})$ was mixed with $3 \mathrm{~mL}$ of reagent solution $(0.6 \mathrm{M}$ sulphuric acid, $28 \mathrm{mM}$ sodium phosphate, and $4 \mathrm{mM}$ ammonium molybdate) and to left to incubate in a water bath at $95^{\circ} \mathrm{C}$, for $90 \mathrm{~min}$. After cooling, the absorbance of the green phosphomolybdenum complex was measured at $695 \mathrm{~nm}$. In the case of the blank, $0.4 \mathrm{~mL}$ of methanol was used replacing the sample. The antioxidant activity was determined using a standard curve of ascorbic acid solution at different concentrations as the standard.

\section{Results and Discussion}

The fat obtained from bee pollen samples were characterized by the determination of saponification value, specific gravity, refractive indices, acid, and iodine values. The fatty acid and mineral composition, and the antioxidant activity of bee pollens were evaluated.

\section{Fat characteristics}

The saponification value is inversely proportional to the molecular weight of the fat (Mello and Pinheiro 2012). The values found in the present work (Table 1), lower than $190-200 \mathrm{mg} \mathrm{KOH.g^{-1 }}$ are characteristic of oils predominantly constituted by triglycerides in which fatty acids have 18 carbon

Table 1. Some physical and chemical properties of pollen fat.

\begin{tabular}{lll}
\hline Characteristics & NA & SA \\
\hline Specific Gravity [at $25^{\circ} \mathrm{C}$ ] & $0.92 \pm 0.00$ & $0.92 \pm 0.00$ \\
Refractive Index [at $25^{\circ} \mathrm{C}$ ] & $1.47 \pm 0.00$ & $1.46 \pm 0.00$ \\
Acid Value & $22.04 \pm 0.15$ & $10.01 \pm 0.12$ \\
Saponification Value & $178.54 \pm 2.40$ & $175.73 \pm 2.20$ \\
Iodine Value (Wijs Method) & $44.42 \pm 1.60$ & $32.90 \pm 1.20$ \\
\hline
\end{tabular}

Mean \pm standard deviation $(n=3)$. atoms, can be partly explained by the presence of arachidic and tricosanoic acid in concentration higher than $1 \%$ (Table 2). The specific gravity lower than 1.0 reveals that both samples are less dense than water, falling within the narrow range reported for vegetable oils $(0.900-0.925)$ (Yahaya et al. 2012; Tesfaye et al. 2016; Yildiz and Dasgupta 2016; Ogunlade and Aremu 2019). The refractive index is within the recommended acceptable levels for edible oils (1.445 and 1.47) (Yahaya et al. 2012; Ogunlade and Aremu 2019).

The acid value represents the quantity of free fatty acids arising from hydrolytic processes. According to the results obtained, NA had higher amounts of free fatty acids than SA. For example, and according to Tesfaye et al. (2016), the acid value of bee wax is highly influenced by agroecology, whereby the differences found in these two samples, although not being waxes, may partially be explained by these factors. In addition, the acid value is also a relative measure of rancidity, since free acidity generally occurs during decomposition of triglycerides (Miguel et al. 2005). Moreover, unsaturated fatty acids are more exposed to oxidation processes than saturated ones. The iodine value is a measure of the degree of unsaturation of fat, and at the same time, it is a measure of vulnerability to oxidation. Higher values of iodine value mean higher oxidation of vulnerability (Ngassapa et al. 2012). The iodine values for samples NA and SA were 44.42 and $32.90 \mathrm{mg} \mathrm{I} 2 . \mathrm{g}^{-1}$ fat, respectively (Table 1 ), which are in accordance with the values found for total unsaturated fatty acids in both samples. NA was richer in unsaturated fatty acids than SA (Table 1).

\section{Fatty acid composition of pollen fat}

The fatty acid compositions of both bee pollens are shown in Table 2. The palmitic, oleic, linoleic, and linolenic acids were the major fatty acids in samples NA and SA. The remaining fatty acids were predominantly saturated ones, namely, myristic acid, stearic acid, arachidic acid, and tricosanoic acid, respectively. Except for tricosanoic and sebacic acids, the remaining fatty acids are common in bee pollen in different percentages (Campos et al. 2008; Özcan et al. 2019). Tricosanoic acid was previously reported 
Table 2. The Fatty acid compositions (\%) of Algerian bee pollens.

\begin{tabular}{|c|c|c|c|c|}
\hline Fatty acid/compound & (IUPAC nomenclature) Fatty acid/compound & & NA [\%] & SA [\%] \\
\hline Lauric acid & Dodecanoic acid & $\mathrm{C} 12: 0$ & $1.6 \pm 0.1$ & $4.4 \pm 0.2$ \\
\hline Sebacic acid & Decanedioic acid & & $0.5 \pm 0.0$ & $4.4 \pm 0.2$ \\
\hline Myristic acid & Tetradecanoic acid & C14:0 & $1.6 \pm 0.1$ & $3.1 \pm 0.2$ \\
\hline Palmitic acid & Hexadecanoic acid & $\mathrm{C} 16: 0$ & $17.0 \pm 0.9$ & $26.5 \pm 1.3$ \\
\hline Unidentified & Unidentified & & $7.0 \pm 0.4$ & $2.5 \pm 0.1$ \\
\hline Linolenic acid & $(9 Z, 12 Z, 15 Z)-O c t a d e c a-9,12,15$-trienoic acid & $\mathrm{C} 18: 3$ & $27.2 \pm 1.4$ & $26.3 \pm 1.3$ \\
\hline Linoleic acid & $(9 \mathrm{Z}, 12 \mathrm{Z})$-Octadeca-9,12-dienoic acid & $\mathrm{C} 18: 2$ & $15.7 \pm 0.8$ & $12.6 \pm 0.6$ \\
\hline Oleic acid & (9Z)-Octadecenoic acid & $\mathrm{C} 18: 1$ & $8.5 \pm 0.4$ & $10.1 \pm 0.5$ \\
\hline Stearic acid & Octadecanoic acid & C18:0 & $2.2 \pm 0.1$ & $2.5 \pm 0.1$ \\
\hline Arachidic acid & Eicosanoic acid & $\mathrm{C} 20: 0$ & $4.4 \pm 0.2$ & $2.8 \pm 0.1$ \\
\hline Tricosanoic acid & Tricosanoic acid & $\mathrm{C} 23: 0$ & $1.5 \pm 0.1$ & $1.0 \pm 0.1$ \\
\hline 17-Pentatriacontene & 17-Pentatriacontene & & $12.9 \pm 0.7$ & $3.8 \pm 0.2$ \\
\hline
\end{tabular}

as being present in citrus and clover bee bread (bee pollen that underwent lactic acid fermentation) collected in Turkey (Kaplan et al. 2016). The presence of decanedioic acid or sebacic acid, a dicarboxylic fatty acid, has been reported in acacia and palm honey (Hegazy and El-Hady 2009). The presence of these fatty acids may be explained by the presence of Citrus and Acacia species near to the hives where bee pollen was collected.

The unsaturated fatty acids constituted 51 and $49 \%$ of the oils of samples 1 and 2, respectively, while the saturated fatty acids were 29 and $45 \%$, respectively; nevertheless, NA had a higher percentage of the alkane 17-pentatriacontene $(12.9 \%)$ than SA $(3.8 \%)$ (Table 2). This compound has been found as a dominant hydrocarbon in propolis (Bayram and Gerçek 2017).

\section{Mineral content}

The mineral content of fat bee pollen is depicted in Table 3. Potassium was the main element present in both fat bee pollen samples, although with significant differences (1497.51 and $513.16 \mathrm{mg} \cdot \mathrm{kg}^{-1}$ in NA and SA, respectively). The second most important element was sodium, at the same level of potassium. Sodium was at higher concentration in SA, where potassium was in lower amount, and NA with higher concentration of potassium had lower concentration of sodium. The third most important element was iron, but significantly lower than potassium and sodium. In contrast to $\mathrm{K}$ that was in higher amounts in NA, the highest amount of $\mathrm{Fe}$ was verified in SA (Table 3) such as for sodium. Copper was present in similar amounts in both samples $\left(\approx 3 \mathrm{mg} \cdot \mathrm{kg}^{-1}\right)$. Sodium, lead and nickel elements were not detected in both samples (Table 3). Pollen grains are a significant source of potassium $(\mathrm{K})$ that remains in lipid fraction, as observed in the present work. Other elements constitute bee pollen grains, but they were not detected in the present work (e.g., phosphorus, calcium, sulfur, magnesium), which contents change depending on the location that involves plant varieties and climatic conditions (Liolios et al. 2019; Özcan et al. 2019). The values of K found in our samples differed significantly from those previously reported (Liolios et al. 2019; Özcan et al. 2019) for bee pollen grains from different regions of Turkey, Russia, and Greece, which can be partially explained by the different matrix used for the determination of mineral elements. In our case, fixed oils were the matrices used in contrast to the general studies that use bee pollen grains (Liolios et al. 2019; Özcan et al. 2019). The present work showed that the fat samples from bee pollen also contain minerals, although much less when compared to the bee pollen matrix.

Table 3. Mineral composition of bee pollen fat.

\begin{tabular}{|c|c|c|}
\hline \multirow[t]{2}{*}{ Mineral } & \multicolumn{2}{|c|}{ Content [mg.kg ${ }^{-1}$; DW } \\
\hline & NA & SA \\
\hline $\mathrm{Na}$ & $235.21 \pm 47.52$ & $1142.47 \pm 95.04$ \\
\hline $\mathrm{K}$ & $1497.51 \pm 38.67$ & $513.16 \pm 116.01$ \\
\hline $\mathrm{Fe}$ & $6.27 \pm 0.80$ & $22.52 \pm 2.62$ \\
\hline $\mathrm{Cu}$ & $3.20 \pm 0.33$ & $3.12 \pm 0.14$ \\
\hline $\mathrm{Pb}$ & ND & ND \\
\hline $\mathrm{Ni}$ & ND & ND \\
\hline
\end{tabular}

Mean \pm SD $(n=3)$; DW: dry weight; ND: not detected. 
Table 4. Phenolic content and antioxidant activities of bee pollen.

\begin{tabular}{llll}
\hline & NA & SA & Ascorbic acid \\
\hline Phenolic content [mg GAE/g]; DW & $7.68 \pm 2.64$ & $29.85 \pm 5.10$ & - \\
IC $_{50}\left[\mathrm{mg} \cdot \mathrm{mL}^{-1}\right]$ DPPH assay & $4.88 \pm 1.02$ & $1.73 \pm 0.08$ & $0.001 \pm 0.000$ \\
$\mathrm{IC}_{50}\left[\mathrm{mg} \cdot \mathrm{mL}^{-1}\right]$ ABTS assay & $2.57 \pm 0.07$ & $3.37 \pm 0.36$ & $0.003 \pm 0.000$ \\
TAC & $0.04 \pm 0.00$ & $0.06 \pm 0.00$ & - \\
\hline
\end{tabular}

GAE: Gallic acid equivalent; DW: dry weight; TAC: Total antioxidant capacity; -: not determined.

\section{Phenolic content and antioxidant activity}

Several biological properties have been attributed to bee pollen (Denisow and Denisow-Pietrzyk 2016). For this reason, the antioxidant activity was determined in both samples from different regions of Algeria. First of all, the total phenol content was evaluated and significant difference was found, being SA much richer in phenols than NA. The total phenol content observed in NA is within the range reported by Özcan et al. (2019) for Turkish and Russian bee pollen grains, but lower when compared to SA. Such difference may explain the best activity of SA in what concerns the ability for scavenging DPPH free radicals. The concentration needed for scavenging $50 \%$ of DPPH free radicals $\left(\mathrm{IC}_{50}=1.73 \mathrm{mg} \cdot \mathrm{mL}^{-1}\right)$ of SA was much lower than $\mathrm{IC}_{50}=4.88 \mathrm{mg} \cdot \mathrm{mL}^{-1}$ for NA (Table 4). If a correlation seems existing between phenol content and DPPH scavenging activity, the same was not observed when the assay for determining the antioxidant activity was that for scavenging the ABTS free radicals (Table 4). This finding can be attributed to the different capacity of diverse structures of phenols for scavenging DPPH or ABTS (Shalabi and Shanab 2013; Badanai et al. 2015). Several antioxidant natural products (compounds and/or extracts) have been reported for their ability to scavenge free radicals and to attenuate their harmful effects (Boulanouar et al. 2013, 2019; Ghareeb et al. 2018a, b, c; Sobeh et al. 2018; Ghareeb et al. 2019; Cheraif et al. 2020). The activities found were significantly inferior to those verified for the reference (ascorbic acid) with $\mathrm{IC}_{50}$ values of 0.001 and $0.003 \mathrm{mg} \cdot \mathrm{mL}^{-1}$, in DPPH and ABTS scavenging activities, respectively. Furthermore, the two samples showed total antioxidant capacity values of 0.04 and 0.06 , for samples NA and SA, respectively. The phosphomolybdenum assay is based on the reduction of Mo (VI) to Mo (V) by the tested bee pollen sample and subsequent creation of a green-colored [phosphate $=$ Mo $(\mathrm{V})$ ] complex at acidic pH (Ghareeb et al. 2013; AbdelAziz et al. 2018; Hamed et al. 2019).

\section{Conclusion}

The fats extracted from bee pollen samples have a saponification index lower than $190 \mathrm{mg} \cdot \mathrm{kg}^{-1}$ $\mathrm{KOH}$, which may be due to the presence of arachidic and tricosanoic acids $\left(\mathrm{C}_{20}\right.$ and $\left.\mathrm{C}_{23}\right)$ in percentages $>1 \%$. The remaining physicochemical parameters are within the range for fixed oils. The fatty acids of pollen fat samples with percentages higher than $10 \%$ were palmitic, oleic, linoleic, and linolenic acids. Among other minor fatty acids, tricosanoic and sebacic acids were detected, which indicate the presence of acacia and other species near the hives. Potassium and sodium were the most important minerals present in bee pollen fat samples; nevertheless, their amounts deeply varied depending on the sample. Bee pollen extracts had different amounts of total phenols, which were determinant in the antioxidant activity, although more significant when the DPPH assay was used.

These results show the importance of floral origin of bee pollen. The biological properties attributed to these bee products are highly dependent on the floral origin. In addition, and in our particular case, the presence of some fatty compounds generally absent in other examples of bee pollen, can be considered as biomarkers: sebacic acid and acacia. Such approach must be deeply studied.

\section{Conflict of Interest}

The authors declare that they have no conflict of interest. 


\section{References}

Abdelnour SA, Abd El-Hack ME, Alagawany M, Farag MR, Elnesr SS (2019) Beneficial impacts of bee pollen in animal production, reproduction and health. J. Anim. Physiol. Anim. Nutr. 103: 477-484.

Abdel-Aziz MS, Ghareeb MA, Saad AM, Refahy LA, Hamed AA (2018) Chromatographic isolation and structural elucidation of secondary metabolites from the soilinhabiting fungus Aspergillus fumigatus 3T-EGY. Acta Chromatogr. 30: 243-249.

AOCS (2003) Official methods and recommended practices of American Oil Chemists' Society. 5 ed. AOCS Press, Champaign.

Badanai J, Silva C, Martins D, Antunes D, Miguel MG (2015) Ability of scavenging free radicals and preventing lipid peroxidation of some phenols and ascorbic acid. J. Appl. Pharm. Sci. 5: 34-41.

Bayram NE, Gerçek YC (2017) Major constituents of different propolis samples. Hacettepe J. Biol. Chem. 45: 581-584.

Boulanouar B, Gherib A, Smail A, Gago C, Miguel MG (2013) Antioxidant activities of eight Algerian plant extracts and two essential oils. Ind. Crops Prod. 46: 85-96.

Boulanouar B, Gherib A, Bronze MR, Ghareeb MA (2019) Identification, quantification, and antioxidant activity of hydroalcoholic extract of Artemisia campestris from Algeria. Turk. J. Pharm. Sci. 16: 234-239.

Cheraif K, Boulanouar B, Gherib A, Bardaweel SK, Ayvaz MC, Flamini G, Ascrizzi R, Ghareeb MA (2020) Chemical composition, antioxidant, anti-tyrosinase, anticholinesterase and cytotoxic activities of essential oils of six Algerian plants. Molecules 25(7): 1710.

Brand-Williams W, Cuvelier ME, Berset C (1995) Use of a free radical method to evaluate antioxidant activity. LWT-Food Sci. Technol. 28: 25-30.

Campos MGR, Bogdanov S, de Almeida-Muradian LB, Azczesna T, Mancebo Y, Frigerio C, Ferreira F (2008) Pollen composition and standardization of analytical methods. J. Apic. Res. 47: 156-163.

Converti A, Casazza AA, Ortiz EY, Perego P, del Borghi M (2009) Effect of temperature and nitrogen concentration on the growth and lipid content of Nannochloropsis oculata and Chlorella vulgaris for biodiesel production. Chem. Eng. Process. 48: 1146-1151.

Denisow B, Denisow-Pietrzyk M (2016) Biological and therapeutic properties of bee pollen: a review. J. Sci. Food Agric. 96: 4303-4309.

Dorman H, Hiltunen R (2004) Fe(III) reductive and free radical-scavenging properties of summer savory (Satureja hortensis L.) extract and subfractions. Food Chem. 88: 193-199.

Gao X, Ohlander M, Jeppsson N, Bjork L, Trajkovski V (2000) Changes in antioxidant effects and their relationship to phytonutrients in fruits of sea buckthorn (Hippophae rhamnoides L.) during maturation. J. Agric. Food Chem. 48: 1485-1490.

Ghareeb MA, Shoeb HA, Madkour HMF, Refahy LA, Mohamed MA, Saad AM (2013) Radical scavenging potential and cytotoxic activity of phenolic compounds from Tectona grandis (Linn.). Global J. Pharmacol. 7: 486-497.

Ghareeb M, Mohamed T, Saad AM, Refahy LA, Sobeh M, Wink M (2018a) HPLC-DAD-ESI-MS/MS analysis of fruits from Firmiana simplex (L.) and evaluation of their antioxidant and antigenotoxic properties. J. Pharm. Pharmacol. 70: 133-142.

Ghareeb MA, Sobeh M, Rezq S, El-Shazly AM, Mahmoud MF, Wink M (2018b) HPLC-ESI-MS/MS profiling of polyphenolics of a leaf extract from Alpinia zerumbet (Zingiberaceae) and its anti-inflammatory, antinociceptive, and antipyretic activities in vivo. Molecules 23: 3238 .

Ghareeb MA, Saad AM, Ahmed WS, Refahy LA, Nasr SM (2018c) HPLC-DAD-ESI-MS/MS characterization of bioactive secondary metabolites from Strelitzia nicolai leaf extracts and their antioxidant and anticancer activities in vitro. Pharm. Res. 10: 368-378.

Ghareeb MA, Sobeh M, El-Maadawy WH, Mohammed HS, Khalil H, Botros SS, Wink M (2019) Chemical profiling of polyphenolics in Eucalyptus globulus and evaluation of its hepato-renal protective potential against cyclophosphamide induced toxicity in mice. Antioxidants 8: 415.

Hamed MM, Ghareeb MA, Shafei AA, Abdel-Aziz MS, Tolba SS (2019) The in vitro evaluation of antioxidant, anticancer and antimicrobial properties of Araucaria heterophylla grown in Egypt. Pharmacol. Online 1: 221235.

Hegazi AG, Abd El-Hady FK (2009) Influence of honey on the suppression of human low-density lipoprotein (LDL) peroxidation (in vitro). Evid. Based Complement. Alternat. Med. 6: 113-121.

Kaplan M, Karaoglu Ö, Eroglu N, Silici S (2016) Fatty acid and proximate composition of bee bread. Food Technol. Biotechnol. 54: 497-504.

Liolios V, Tananaki C, Papaioannou A, Kanelis D, Rodopoulou M-A, Argena N (2019) Mineral content in monofloral bee pollen: investigation of the effect of the botanical and geographical origin. J. Food Meas. Charact. 13: 1674-1682.

Mello LD, Pinheiro MF (2012) Aspectos físico-químicos de azeites de oliva e de folhas de oliveira provenientes de cultivares do RS, Brasil. Alim. Nutr. Araraquara. 23: 537-548.

Miguel MG, Falcato-Simões M, Figueiredo AC, Barroso JMG, Pedro LG, Carvalho LM (2005) Evaluation of the antioxidant activity of Thymus capitata, Thymus mastichina and Thymus camphoratus essential oils. J. Food Lipids 12: 181-197.

Ngassapa FN, Nyandoro SS, Mwaisaka TR (2012) Effects of temperature on the physicochemical properties of traditionally processed vegetable oils and their blends. Tanz. J. Sci. 38: 166-176.

Ogunlade CA, Aremu AK (2019) Influence of processing conditions on some physical characteristics of vegetable oil expressed mechanically from Pentaclethera macrophylla Benth kernels: response surface approach. J. Food Process Eng. 42: e12967. 
Özcan MM, Aljuhaimi F, Babiker EE, Uslu N, Ceylan DA, Ghafoor K, Özcan MM, Dursun N, Ahmed IM, Jamiu FG, Alsawmahi ON (2019) Determination of antioxidant activity, mineral contents and fatty acid compositions of bee pollen grains collected from different locations. J. Apic. Sci. 63: 69-79.

Öztürk M, Tel G, Öztürk FA, Dur ME (2014) The cooking effect on two edible mushrooms in Anatolia: fatty acid composition, total bioactive compounds, antioxidant and anticholinesterase activities. Rec. Nat. Prod. 8: 189194.

Prieto P, Pineda M, Aguila M (1999) Spectrophotometric quantitation of antioxidant capacity through the formation of a phosphomolybdenum complex: Specific application to the determination of vitamin E. Anal. Biochem. 269: 337-341.

Rebiai A, Lanez T (2013) A facile electrochemical analysis to determine antioxidant activity of bee pollen. Int. Lett. Chem. Phys. Astr. 14: 31-38.

Rebiai A, Lanez T (2012) Chemical composition and antioxidant activity of Apis mellifera bee pollen from Northwest Algeria. J. Fund. App. Sci. 4: 26-35.

Rebiai A, Lanez T, Belfa ML (2014) Determination of caffeic acid and gallic acid in Algerian bee pollen by an HPLC method. PCBS. J. 8: 190-197.

Shalabi EA, Shanab SMM (2013) Comparison of DPPH and ABTS assays for determining antioxidant potential of water and methanol extracts of Spirulina platensis. Ind. J. Geo-Mar. Sci. 42: 556-564.

Sobeh M, Mahmoud MF, Hasan RA, Abdelfattah MAO, Sabry OM, Ghareeb MA, El-Shazly AM, Wink M (2018) Tannin-rich extracts from Lannea stuhlmannii and Lannea humilis (Anacardiaceae) exhibit hepatoprotective activities in vivo via enhancement of the anti-apoptotic protein Bcl-2. Sci. Rep. 8: 9343.

Tesfaye B, Begna D, Eshetu M (2016) Analysis of physicochemical properties of beeswax produced in Bale natural forest, South-Eastern-Ethiopia. Eur. Biophys. J. 4: 42-46.

Ullah N, Ali J, Khan FA, Khurram M, Hussain A, Inayat-urRahman, ur-Rahman Z, Shafqatullah (2012) Proximate composition, minerals content, Antibacterial, and antifungal activity evaluation of pomegranate (Punica granatum L.) peels powder. Middle East J. Sci. Res. 11: 396-401.

Yahaya AT, Taiwo O, Shittu TR, Yahaya LE, Jayeola CO (2012) Investment in cashew kernel oil production: cost and return analysis of three processing methods. Am. J. Econ. 2: 45-49.

Yildiz Y, Dasgupta M (2016) Unsaponifiable matter in carnuba (Cera carnuba) wax, a modification of the USP/NF and FCC methods. Am. J. Anal. Chem. 7: 611-616. 